COSTING:Journal of Economic, Business and Accounting

Volume 4 Nomor 2, Juni 2021

e-ISSN : 2597-5234

IDMEKpe

\title{
Pengaruh Citra Merek Dan Electronic Word Of Mouth Terhadap Minat Beli Produk Kecantikan Wardah
}

\section{THE EFFECT OF BRAND IMAGE AND ELECTRONIC WORD OF MOUTH ON THE INTERESTS OF BUYING BEAUTY PRODUCTS WARDAH}

\author{
Novia Roudhlotul Janah ${ }^{1}$, Edi Suswardji ${ }^{2}$ \\ Universitas Singaperbangsa Karawang,Indonesia ${ }^{1,2}$ \\ 1610631020276@student.unsika.ac.id ${ }^{1}$
}

\begin{abstract}
This research aims to find out how big the brand image and Electronic Word Of Mouth affect the buying interest in Wardah beauty products. The study used a descriptive and vernacular approach to sampling techniques using Nonprobability Sampling with respondents amounting to 135 . Data were analyzed using path analysis with SPSS version 26. The result of the relationship between brand image and electronic word of mouth has a correlation coefficient of 0.498 and has a medium and direct relationship level due to positive values, the partial effect of brand image on buying interest is $24.7 \%$, indicating that brand image has a positive influence with buying interest, the partial effect of electronic word of mouth on buying interest is $18.2 \%$. It shows that electronic word of mouth on buying interest has a positive effect, the simultaneous effect of brand image and electronic word of mouth on buying interest amounted to $43.1 \%$. This shows that the variable brand image and electronic word of mouth have a strong enough influence on buying interest Wardah beauty products. But there are still other variable factors not examined around $56.9 \%$
\end{abstract}

Keywords : Brand Image, Electronic Word of Mouth, Buying Interest.

\begin{abstract}
ABSTRAK
Penelitian ini bertujuan untuk mengetahui seberapa besar pengaruh citra merek dan Electronic Word Of Mouth terhadap Minat Beli pada produk kecantikan Wardah. Penelitian ini menggunakan pendekatan deskriptif verifikatif dan teknik pengambilan sampel menggunakan Nonprobability Sampling dengan responden berjumlah 135. Data dianalisis menggunakan path analysis dengan program SPSS versi 26. Hasil dari penelitian ini menunjukan hubungan antara citra merek dan electronic word of mouth memiliki koefisien korelasi sebesar 0,498 dan mempunyai tingkat hubungan yang sedang dan searah karena nilai positif, pengaruh parsial citra merek terhadap minat beli adalah sebesar $24,7 \%$ ini menunjukkan bahwa citra merek memiliki pengaruh positif dengan minat beli, pengaruh parsial electronic word of mouth terhadap minat beli adalah sebesar $18,2 \%$ ini menunjukkan bahwa electronic word of mouth terhadap minat beli memiliki pengaruh positif, Pengaruh simultan citra merek dan electronic word of mouth terhadap minat beli sebesar $43,1 \%$. Hal ini menunjukkan bahwa variabel citra merek dan electronic word of mouth memiliki pengaruh yang cukup kuat terhadap minat beli produk kecantikan Wardah. Namun masih ada faktor variabel lain yang tidak diteliti sebesar $56,9 \%$.
\end{abstract}

Kata Kunci : Citra Merek, Electronic Word of Mouth, Minat Beli 


\section{PENDAHULUAN}

Bidang industri kecantikan di Indonesia saat ini mengalami peningkatan yang signifikan. Negara Indonesia merupakan salah satu pangsa pasar produk kosmetik atau kecantikan yang cukup potensial sehingga usaha ini menjanjikan bagi produsen yang ingin mengembangkannya, Dirjen Industri Kimia Tekstil dan Aneka (IKTA).

Kementerian Perindustrian Republik Indonesia, Achmad Sigit Dwiwahjono di Jakarta, Kamis (19/7). Kemenperin mencatat, pada tahun 2017 industri kosmetik nasional berkembang mencapai $6,35 \%$ dan naik menjadi $7,36 \%$ di triwulan $\mathrm{I} / 2018$. Industri kosmetik di dalam negeri yang semakin bertambah sebanyak 153 perusahaan pada tahun 2017, sehingga total perusahaan kosmetik saat ini mencapai lebih dari 760 perusahaan. Berdasarkan total tersebut, sebanyak $95 \%$ industri kosmetik nasional merupakan sektor industri kecil dan menengah (IKM) dan sisanya industri skala besar (Kemenparin.go.id). Artikel yang ditulis (Global Business Guide) menyatakan bahwa di Negara Indonesia, pertumbuhan angka penjualan industri kosmetik didorong oleh permintaan pasar yang meningkat. Populasi wanita Indonesia sebagai pengguna kosmetik saat ini telah mencapai 126,8 juta orang. (www.marketeers.com)

Nilai pasar industri kosmetik yang dihitung berdasarkan kompilasi dan estimasi mencakup produk kosmetik buatan lokal maupun impor (www.duniaindustri.com). Produk kosmetik itu meliputi produk berbasis kecantikan mulai dari lipstick, bedak, blush on, pelembab kulit, produk pemutih kulit, krim wajah, produk spa, minyak wangi dan deodorant, produk perawatan tubuh, produk pewarna rambut, dan lain-lain.
Dwiwahjono di Jakarta, Kamis (19/7). Kemenperin mencatat, pada tahun 2017 industri kosmetik nasional berkembang mencapai $6,35 \%$ dan naik menjadi $7,36 \%$ di triwulan $\mathrm{I} / 2018$. Industri kosmetik di dalam negeri yang semakin bertambah sebanyak 153 perusahaan pada tahun 2017, sehingga total perusahaan kosmetik saat ini mencapai lebih dari 760 perusahaan. Berdasarkan total tersebut, sebanyak 95\% industri kosmetik nasional merupakan sektor industri kecil dan menengah (IKM) dan sisanya industri skala besar (Kemenparin.go.id). Artikel yang ditulis (Global Business Guide) menyatakan bahwa di Negara Indonesia, pertumbuhan angka penjualan industri kosmetik didorong oleh permintaan pasar yang meningkat. Populasi wanita Indonesia sebagai pengguna kosmetik saat ini telah mencapai 126,8 juta orang. (www.marketeers.com)

Nilai pasar industri kosmetik yang dihitung berdasarkan kompilasi dan estimasi mencakup produk kosmetik buatan lokal maupun impor (www.duniaindustri.com). Produk kosmetik itu meliputi produk berbasis kecantikan mulai dari lipstick, bedak, blush on, pelembab kulit, produk pemutih kulit, krim wajah, produk spa, minyak wangi dan deodorant, produk perawatan tubuh, produk pewarna rambut, dan lain-lain.

Minat diilustrasikan sebagai suatu situasi seseorang sebelum melakukan tindakan yang dapat dijadikan dasar untuk memprediksi perilaku. Hal ini sesuai dengan pernyataan terdahulu Raharjo \& Mulyanto, (2018) minat beli merupakan suatu aktivitas yang dilakukan konsumen dalam menilai suatu produk sebelum melakukan keputusan pembelian. Pemasar perlu mengetahui minat beli konsumen terhadap suatu produk agar 
keperluan konsumen dimasa yang akan datang bisa diprediksi dengan baik.

Perilaku konsumen selalu dipengaruhi oleh sejumlah rangsangan yang muncul dari lingkungan eksternal konsumen, yang selanjutnya diproses untuk penyesuaian dengan karakteristik pribadi konsumen sebagai motivasi yang menggambarkan minat konsumen pada produk. Menurut Durianto (2013) mengungkapkan bahwa minat beli adalah keinginan untuk memiliki produk, minat beli akan timbul apabila seseorang konsumen sudah terpengaruh terhadap mutu dan kualitas dari suatu produk, informasi seputar produk seperti: harga, cara membeli dan kelemahan serta keunggulan produk dibanding brand lain. Berdasarkan pendapat ahli di atas dapat dikatakan bahwa minat beli tersebut timbul dari dalam diri seorang konsumen yang terpengaruh dari ulasan produk tersebut. Selain itu ada faktorfaktor lain yang mempengaruhi minat beli seorang konsumen yaitu : kualitas produk, citra merek, harga, lokasi dan kualitas pelayanan.

Berdasarkan data Tokopedia yang diolah penulis menunjukan bahwa produk kecantikan merek wardah masih kalah dengan Emina yang masih satu naungan yaitu Grup Paragon Technology and Innovation. Wardah kalah oleh Emina yang bisa dibilang kosmetik pendatang baru. Bahkan pada saat ajang Sociolla Award 2019, wardah pun tidak masuk kedalam kategori produk kecantikan (suara.com). Semakin hari eksistensi produk wardah semakin bergeser dengan adanya produk pesaing yang baru-baru ini banyak bermunculan.

Merek mampu menjadi pembeda antara produk pesaing, tanpa adanya merek yang kuat maka produk tidak akan dikenal oleh masyarakat luas. Jika merek tidak dikenal, maka akan mengakibatkan kerugian bagi pihak perusahaan. Cara yang dapat digunakan agar merek mudah melekat atau diingat dalam benak konsumen yaitu dengan meningkatkan kualitas dari merek tersebut. Jika memiliki Kualitas yang bagus maka merek tersebut akan menarik perhatian konsumen dan dapat menciptakan kesan positif bagi para konsumen. Konsumen beranggapan bahwa merek dapat memberikan nilai tambah bagi mereka.

Perusahaan harus memiliki citra merek yang baik. Citra merek merupakan salah satu asset bagi perusahaan, karena dengan adanya citra merek tersebut akan memberikan dampak kepada persepsi konsumen dimana konsumen akan memiliki kesan positif terhadap merek tersebut. Pernyataan ini diperkuat dari penelitian terdahulu Raharjo \& Mulyanto, (2018). salah satu cara agar produk mempunyai posisi strategis di pasar dan mampu bertahan di pasaran dengan jangka waktu yang lama, serta dapat bersaing dengan produk lainnya di pasaran. Citra Merek mempunyai peran penting yaitu untuk membedakan suatu perusahaan atau produk dengan yang lain.

Perkembangan informasi yang sangat cepat didapatkan membuat masyarakat mudah mengetahui tentang tren yang up to date. Zaman yang semakin canggih penyebaran informasi dapat dilakukan melalui berbagai cara, yaitu melalui YouTube, instagram, facebook, twitter, dan lain sebagainya. Sosial media ini bisa mengakses, mengupdate, dan mempublikasikan informasi melalui teknologi baru, seperti video digital, blogging, foto dari smartphone.

Belakangan ini video blog (vlog) di YouTube menjadi suatu hal yang fenomenal di Indonesia. Perkembangan jumlah pengguna di seluruh dunia semakin bertambah, karena saat ini YouTube tidak hanya bisa digunakan untuk menggunggah video saja tetapi 
bisa juga digunakan untuk media periklanan dengan konten vlog. Di negara Indonesia, penggunaan YouTube sangat tinggi, terbukti dari data presentase yang dilakukan oleh Hootsuite We Are Social. Menurut Kotler \& Keller (2016) media sosial adalah media yang digunakan oleh konsumen untuk berbagi pesan teks, gambar, maupun video informasi dengan orang lain atau perusahaan.

Ulasan yang paling banyak diunggah oleh beauty vlogger sebagai electronic Word of Mouth adalah mengenai produk kosmetik. Kosmetik merupakan salah-satu industri yang sadar akan pentingnya strategi pemasaran electronic Word of Mouth untuk menarik konsumen. Industriindustri kosmetik melakukan berbagai inovasi dan promosi dalam memperkenalkan produk mereka. Wardah merupakan salah satu produk kosmetik yang diproduksi oleh PT Paragon. PT.Paragon merupakan salah satu industri yang menggunakan strategi komunikasi pemasaran electronic Word of Mouth dalam mempromosikan produk kosmetik mereka melalui media sosial Youtube, melalui ulasan yang disampaikan oleh beauty vlogger. Trennya sekarang ini ke people bukan hanya logo saja, konsumen saat ini lebih percaya experience. Belum lagi sosial media sangat booming, jadi memang konsep influencer ini berpengaruh untuk pendampingan konsumen.

Banyaknya bentuk kegiatan pemasaran yang dilakukan bertujuan untuk menarik perhatian konsumen terhadap produk wardah. Cukup dengan mensponsori ataupun memberi secara cuma-cuma produk kecantikan yang produsen miliki kepada para beauty vlogger tersebut, secara tidak langsung beauty vlogger berkewajiban untuk mengulas baik dan buruk produk yang mereka terima ke penonton YouTube.
Hal ini lah yang menimbulkan minat beli bagi para penontonnya untuk mencoba setiap produk yang diulas oleh para beauty vlogger. Sehingga dari uraian tersebut diduga bahwa beauty vlogger merupakan seseorang atau kelompok yang membuat vlog untuk merekomedasikan dan mengulas tentang kecantikan serta produk yang digunakan.

Penelitian yang akan saya teliti ini sebelumnya telah dilakukan oleh Eriza, (2017) tentang Peran Mediasi Citra Merek dan Persepsi Risiko Pada Hubungan Antara Electronic Word Of Mouth (E-Wom) dan Minat Beli (Studi Pada Konsumen Kosmetik E-Commerce Di Solo Raya). Variabel yang digunakan pada penilitian di atas memiliki kesamaan dengan variable yang akan diteliti.

\section{METODE PENELITIAN}

Dalam penelitian ini metode penelitian yang digunakan adalah metode penelitian deskriptif verifikatif. Penulis juga menggunakan data kuantitatif karena metode kuantitatif memberikan penjelasan yang tepat pada fakta yang sedang dihadapi dan metode kuantitatif mempunyai keunggulan dari sisi efisiensi.

Variabel independen dalam penelitian ini yaitu Citra Merek (X1) dan Electronic Word of Mouth (X2). Variabel dependen adalah variabelvariabel yang dipengaruhi atau yang menjadi akibat, karena adanya variabel bebas. Variabel dependen dalam penelitian ini yaitu Minat Beli (Y)

Penelitian ini, yang akan menjadi target populasi adalah konsumen wanita generasi millenial pengguna produk kecantikan Wardah yang berada di Kabupaten Karawang, sehingga jumlah dari populasi tidak diketahui secara pasti.

Metode pengambilan sampel yang digunakan pada penelitian ini 
adalah Nonprobability Sampling dengan teknik Sampling Incidental yaitu pengambilan sampel berdasarkan kebetulan, yakni siapa saja yang secara kebetulan/incidental bertemu dengan peneliti dapat digunakan sebagai sampel, bila dipandang orang yang kebetulan ditemui itu cocok sebagai sumber data maka besarnya sampel yang digunakan sebanyak 135 sampel.

Penelitian ini menggunakan metode pengumpulan data dengan Kuisioner (angket) yaitu teknik pegumpulan data yang dilakukan dengan cara memberi seperangkat pernyataan tertulis kepada responden untuk dijawabnya.

\section{HASIL DAN PEMBAHASAN Uji Validitas dan Uji Realibilitas}

Berdasarkan hasil pengujian validitas ketiga variabel dalam setiap dimensi dinyatakan valid karena nilai $r$ variabel X1 Citra merek, X2 E-WOM dan Y Minat Beli lebih dari 0,300.

Dapat diketahui dari hasil uji reliabilitas untuk masing-masing variabel, Variabel citra merek, electronic word of mouth, dan minat beli memiliki nilai $r>0,6$ yang artinya reliabel.

\section{Uji Normalitas}

Pada uji normalitas Setelah menggunakan monte carlo nilai signifikan $>0,05$ dan data sudah normal. Sehingga hasil analisis tersebut dapat dilanjutkan ke asumsi klasik selanjutnya.Hasil Analisis Data

\section{Analisis Deskriftif}

Berdasarkan hasil penelitian menunjukkan bahwa Citra Merek pada produk kecantikan Wardah berdasarkan hasil kuesioner diperoleh total skor sebesar 6299 dengan rata - rata skor sebesar 525 berada pada rentang skala 459 - 567 dengan kriteria setuju. Artinya para responden memberikan respon yang baik terkait produk kecantikan Wardah

Berdasarkan hasil penelitian menunjukkan bahwa Electronic Word Of Mouth pada produk kecantikan Wardah berdasarkan hasil kuesioner diperoleh total skor sebesar 4168 dengan rata rata skor sebesar 464 berada pada rentang skala 459 - 567 dengan kriteria setuju. Artinya para responden memberikan respon yang baik terkait produk kecantikan Wardah

Berdasarkan hasil penelitian menunjukkan bahwa Electronic Word Of Mouth pada produk kecantikan Wardah berdasarkan hasil kuesioner diperoleh total skor sebesar 2867 dengan rata rata skor sebesar 478 berada pada rentang skala 459 - 567 dengan kriteria setuju. Artinya para responden memberikan respon yang baik terkait produk kecantikan Wardah.

\section{Analisis Verifikatif \\ Korelasi Antara Variabel Bebas}

Analisis diperoleh koefisien korelasi diantara variabel bebas Citra Merek (X1) dan Electronic Word Of Mouth (X2) dapat dinilai sebesar 0,498 yang berarti mempunyai tingkat keterkaitan yang kuat dan mempunyai hubungan searah karena nilainya positif.

\section{Koefisien Determinasi Secara Parsial Citra Merek (X1) dan Electronic Word Of Mouth (X2) terhadap Minat Beli}

Berdasarkan hasil perhitungan koefisien determinasi didapatkan nilai sebesar 0,177 , artinya variabel minat beli dipengaruhi langsung oleh variabel citra merek sebesar $17,7 \%$

Berdasarkan hasil perhitungan koefisien determinasi didapatkan nilai sebesar 0,112 , artinya variabel minat beli dipengaruhi langsung oleh variabel electronic word of mouth sebesar 11,2\%. 


\begin{abstract}
Koefisien Determinasi Secara Simultan

Uji Koefisien Determinasi menunjukan bahwa koefisien determinasi sebesar 0,431 berarti $43,1 \%$. Artinya bahwa citra merek dan electronic word of mouth memiliki kontribusi terhadap minat beli sebesar $43,1 \%$ sedangkan sisanya $1-43,1=0,569$ atau $56,9 \%$ merupakan kontribusi variabel lain yang tidak diteliti dalam penelitian ini.
\end{abstract}

\section{Hasil Pengujian Hipotesis \\ Korelasi Antara Citra Merek dan Electronic Word Of Mouth}

Pengujian hipotesis hubungan antara Tingkat Pendidikan dan Pelatihan dilakukan dengan menggunakan uji statistik t, yaitu dengan menggunakan rumus sebagai berikut :

$$
t=\frac{r \sqrt{n-2}}{\sqrt{1-r^{2}}}
$$

Diketahui : $r=0,498 \mathrm{n}=135$

Maka :

$$
\begin{gathered}
t=\frac{r \sqrt{n-2}}{\sqrt{1-r^{2}}} \\
t=\frac{0,498 \sqrt{135-2}}{\sqrt{1-0,498^{2}}} \\
t=\frac{0,498(11,532)}{\sqrt{1-0,248}} \\
t=\frac{5,742}{0,867} \\
t=6,622
\end{gathered}
$$

T-hitung di atas selanjutnya dibandingkan dengan ttabel pada tingkat kesalahan 5\%. df $=\mathrm{n}-2=135-2=133$, maka diperoleh ttabel $=0,1690$ dengan demikian diketahui thitung $(6,622)>$ ttabel 0,1690 maka dapat dinyatakan bahwa $\mathrm{H} 0$ ditolak $\mathrm{H} 1$ diterima, artinya terdapat hubungan yang signifikan antara hubungan Citra Merek dan Electronic Word Of Mouth.

\section{Uji Hipotesis Pengaruh Secara Parsial Citra Merek dan Electronic Word Of Mouth Terhadap Minat Beli \\ Berdasarkan Uji t Menunjukkan} nilai sig. $(0,000)<\alpha(0,05)$ dan $t$ hitung $(5,563)>t$ tabel (1.656) maka H0 ditolak. Dengan demikian, dapat disimpulkan bahwa Citra Merek berpengaruh terhadap Minat Beli.

Berdasarkan Uji t Menunjukkan nilai sig. $(0,000)<\alpha(0,05)$ dan $t$ hitung $(4,438)>\mathrm{t}$ tabel $(1,656)$ maka $\mathrm{HO}$ ditolak. Dengan demikian, dapat disimpulkan bahwa Electronic Word Of Mouth berpengaruh secara significant terhadap Minat Beli

\section{Uji Hipotesis Pengaruh Secara Simultan Citra Merek dan Electronic Word Of Mouth Terhadap Minat Beli}

Pada uji simultan 8 Menunjukkan bahwa $f$ hitung $=50.016$ dan sig 0,000 . Dapat dinyatakan bahwa $\mathrm{f}$ hitung lebih besar dari f tabel $(50.016>3.91)$ dan memiliki signifikansi 0,000 menunjukkan tingkat singnifikan lebih kecil dari $\alpha(0,000<0,05)$ artinya $\mathrm{H} 0$ ditolak, maka H1 diterima. Dengan demikian dapat disimpulkan bahwa hubungan Citra Merek dan Electronic Word Of Mouth secara simultan berpengaruh terhadap Minat Beli.

\section{Pengaruh Parsial Citra Merek Terhadap Minat Beli}

Pengaruh parsial Citra Merek terhadap minat beli adalah sebesar 24,7\%. Menurut Zeithml \& Bitner dalam Ambarwati, et.al, (2015) pengaruh variabel citra merek terhadap minat beli adalah signifikan. Menurut Kotler \& Keller (2016) brand image atau citra merek adalah persepsi dan keyakinan yang dipegang oleh konsumen, seperti yang dicerminkan asosiasi yang tertanam dalam ingatan konsumen. Hal ini ditunjukkan bahwa citra merek memiliki pengaruh positif dengan minat beli. Hal 
ini diperkuat oleh hasil penelitian Ambarwati et al., (2015), Raharjo \& Mulyanto, (2018).

\section{Pengaruh Parsial Electronic Word Of Mouth Terhadap Minat Beli}

Pengaruh parsial electronic word of mouth terhadap minat beli adalah sebesar 18,2\%. Menurut Sameti et.,al dalam Alnefaie et al, (2019), Electronic Word Of Mouth (E-WOM) communication is a form of social interaction as it can be used for sharing information and experiences". Artinya "kata elektronik dari mulut ke mulut adalah bentuk interaksi sosial karena dapat digunakan untuk berbagi informasi dan pengalaman". Hal ini menunjukkan bahwa electronic word of mouth terhadap minat beli memiliki pengaruh positif. Hasil tersebut menjelaskan bahwa electronic word of mouth akan mendorong konsumen memberikan rekomendasi mengenai produk terhadap konsumen lain. Hal ini diperkuat oleh hasil penelitian Jalilvand dalam Eriza, (2017), Virenabia \& Oktafani, (2018), Laksmi \& Oktafani (2016)

\section{Pengaruh Simultan Citra Merek Dan Electronic Word Of Mouth Terhadap Minat Beli Produk Kecantikan Wardah}

Pengaruh simultan citra merek dan electronic word of mouth terhadap minat beli Produk Kecantikan Wardah yaitu sebesar $41,3 \%$. Sedangkan sisanya $56,9 \%$ merupakan pengaruh dari variabel yang tidak diteliti $(\varepsilon)$. Hal ini diperkuat oleh beberapa penelitian Virenabia \& Oktafani, (2018) Pengaruh Electronic Word Of Mouth (Ewom) Sebagai Media Promosi Terhadap Minat Beli Pada Followers Instagram Bandung Makuta, dan Agatha et al., (2019) penelitiannya yang berjudul Pengaruh Brand Image Dan Electronic Word Of Mouth Terhadap Minat Beli Konsumen
Oriflame Di Manado.

\section{PENUTUP \\ Kesimpulan}

Berdasarkan hasil penelitian dan pembahasan yang dilakukan oleh penulis, maka dapat diambil beberapa kesimpulan, yaitu :

1. Pengaruh Parsial citra merek terhadap minat beli produk kecantikan Wardah, sebesar 24,7\%. Maka pengaruh variabel citra merek terhadap minat beli adalah signifikan.

2. Pengaruh Parsial electronic word of mouth terhadap minat beli produk kecantikan Wardah sebesar 18,2\%. Hal ini menunjukkan bahwa electronic word of mouth terhadap minat beli memiliki pengaruh positif.

3. Pengaruh simultan citra merek dan electronic word of mouth terhadap minat beli produk kecantikan Wardah sebesar 0,431 atau $43,1 \%$. Hal ini menunjukan bahwa variabel citra merek dan electronic word of mouth memiliki pengaruh yang sedang terhadap minat beli produk kecantikan Wardah. Namun masih ada faktor variabel lain yang tidak diteliti sebesar 0,569 atau 56,9\%

\section{Saran}

Hasil penelitian ini diharapkan dapat dijadikan sebagai bahan rujukan bagi peneliti selanjutnya yakni dalam program studi Manajemen. Peneliti selanjutnya diharapkan dapat meneliti variabel lain yang belum di teliti. Peneliti selanjutnya diharapkan meneliti objek penelitian yang lain, terutama pada usaha yang bergerak dalam industri kecantikan seperti PT paragon technology and innovation ini 
DAFTAR PUSTAKA

Agatha, C., Tumbel, A., Soepeno, D., Sam, U., \& Manado, R. (2019). Pengaruh Brand Image Dan Electronic Word of Mouth Terhadap Minat Beli Konsumen Oriflame Di Manado. Jurnal EMBA: Jurnal Riset Ekonomi, Manajemen, Bisnis Dan Akuntansi, 7(1), 131-140.

Ambarwati, M., Sunarti, \& Mawardi, M. K. (2015). Survei Pada Mahasiswa Universitas Brawijaya yang Menggunakan Pasta Gigi Pepsodent. 25(1)

Alnefaie, M., Khan, S., \& Muthaly, S. (2019). Consumers' electronic word of mouth-seeking intentions on social media sites concerning Saudi bloggers' YouTube fashion channels: an eclectic approach. International Journal of Business Forecasting and Marketing Intelligence, 5(1),

Durianto, D. (2013). Strategi Menaklukan Pasar Melalui Riset Ekuitas dan Perilaku Merek (Cet. Ke-10). Jakarta: PT Gramedia Pustaka Utama.

Eriza, Z. N. (2017). Peran Mediasi Citra Merek dan Persepsi Risiko pada Hubungan antara Electronic Word of Mouth (E-WOM) dan Minat Beli (Studi pada Konsumen Kosmetik ECommerce di Solo Raya). Komuniti: Jurnal Komunikasi Dan Teknologi Informasi, 9(1), 14.

Kotler, P. \& Keller. K, L. (2016). Marketing Management - 15/E. Harlow : Pearson Education

Laksmi, A. A., \& Oktafani, F. (2016). Pengaruh Electronic Word Of
Mouth (Ewom) Terhadap Minat Beli Followers Instagram Pada Warunk Upnormal. Jurnal Computech \& Bisnis, 10(2), 7888.

Raharjo, R. M., \& Mulyanto, H. (2018). Kualitas Produk, Citra Merek dan Minat Beli Konsumen Keripik Singkong. Jurnal Manajemen Kewirausahaan, 15(1), 109.

Raharjo, R. M., \& Mulyanto, H. (2018). Kualitas Produk, Citra Merek Dan Minat Beli Konsumen Keripik Singkong. Jurnal Manajemen Kewirausahaan, 15(1), 109.

Virenabia, C., \& Oktafani, F. (2018). Pengaruh Electronic Word Of Mouth (EWOM ) Sebagai Media Promosi terhadap Minat Beli Pada Followers Instagram Bandung Makuta. E-Proceeding of Management, 5(1), 10001009. 